\title{
Tuberculoid Granuloma in the Brainstem: Case Report
}

\section{Granuloma tuberculoide no tronco cerebral: relato de caso}

Tobias Ludwig ${ }^{1}$ Luiz Pedro Willimann Rogerio ${ }^{1}$ Marcelo Martins dos Reis ${ }^{1}$ Leandro Pelegrini de Almeida ${ }^{1}$ Gabriel Greggianin Frizzon ${ }^{1}$ Guilherme Finger ${ }^{1}$ Pasquale Gallo ${ }^{1}$ Jennyfer Paulla Galdino Chaves ${ }^{2}$

${ }^{1}$ Department of Neurosurgery, Hospital Cristo Redentor, Porto Alegre, RS, Brazil

${ }^{2}$ Department of Neurosurgery, Hospital Cajuru, Curitiba, PR, Brazil Arq Bras Neurocir 2019;38:64-67.
Address for correspondence Jennyfer Paulla Galdino Chaves, MD, Rua Washington Luis, 50/1.004, Rio de Janeiro, RJ, Brazil. CEP: 20230-025 (e-mail: jennyfergaldino@hotmail.com).

\begin{abstract}
Keywords

- tuberculoma

- granulomatous tuberculosis

- brainstem

Resumo

Palavras-chave

- tuberculoma

- granuloma tuberculoide

- tronco cerebral

Meningitis or meningoencephalitis are the most common presentations of Koch bacilli infection on the central nervous system (CNS), especially in immunosuppressed patients, in whom the bacilli normally reaches the meninges and the cerebral parenchyma.. A least common pathological presentation is the tumoral growth pattern disease known as tuberculoma. This pathological entity is more common in the cerebral hemispheres and is rarely located in the brainstem. The present case report describes a case of a 55-year-old patient under regular antiretroviral therapy who was hospitalized with signs of brainstem and cerebellar disturbances. Computed tomography (CT) and magnetic resonance imaging (MRI) of the brain showed an exophytic lesion in the dorsal region of the pons. The patient underwent total resection of the lesion and the histopathologic analysis was consistent with a tuberculoma.

O acometimento do sistema nervoso central pelo bacilo de Koch é comum, principalmente em pacientes imunossupressos, nos quais normalmente atinge as meninges e o parênquima cerebral, causando quadro de meningite ou meningoencefalite. Contudo, menos comumente, tal acometimento pode formar lesões expansivas conhecidas como tuberculomas. A presença deste tipo de tumoração predomina no parênquima supratentorial, sendo rara sua localização no tronco cerebral. O presente relato de caso tem por objetivo descrever o caso de um paciente de 55 anos, em uso de terapia antirretroviral, que apresentou inicialmente síndrome piramidal alterna com componentes cerebelares. Tomografia e ressonância magnética de crânio mostraram a presença de lesão expansiva exofítica em região dorsal da ponte, no assoalho do quarto ventrículo. O paciente foi submetido à ressecção total da lesão, e o exame anatomopatológico foi compatível com tuberculoma.
\end{abstract}

\section{Introduction}

The World Health Organization (WHO) estimates that a third of the population of the world is infected with Mycobacterium tuberculosis; people coinfected with HIV are at a greater risk of developing the active and widespread form of the disease, including central nervous system (CNS) involvement. ${ }^{1}$ However, only $50 \%$ of the cases of neurotuberculosis are associated with active extraneural received

March 16, 2016

accepted

August 30, 2016
DOI https://doi.org/

10.1055/s-0036-1594250. ISSN 0103-5355.
Copyright $\odot 2019$ by Thieme Revinter Publicações Ltda, Rio de Janeiro, Brazil
License terms

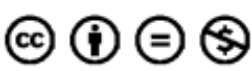


tuberculosis, and its incidence is increasing in people $<20$ years old. ${ }^{2}$

Clinically, the most common manifestation is neurotuberculosis, meningeal disease, but parenchymatous involvement secondary to tuberculomas, tuberculous abscesses, focal cerebritis or tuberculous allergic encephalopathy are also possible. $^{2-7}$

To broaden the understanding of the diagnosis and of the treatment of brainstem tuberculomas, the present case report describes a case and discusses its possible differential diagnoses.

\section{Case Report}

Male patient, 55 years old, presenting with right-sided paresthesia, ataxia and diplopia for 1 week. During the anamnesis, the patient reported positivity to human immunodeficiency virus (HIV) and to hepatitis $\mathrm{C}$ virus (HCV) and antiretroviral therapy use (efavirenz, lamivudine and zidovudine). His treatment was followed-up by an infectious disease specialist, and tests performed shortly before hospitalization showed a CD4 count of 387 and a viral load of $\log 2.9$. The patient was alert, with adequate level and content of consciousness. The physical examination of the cranial nerves showed internuclear ophthalmoplegia and left-sided conjugate gaze palsy. He presented with facial sensitivity with clear right-sided facial hypoesthesia and left peripheral facial paralysis, but with no disfiguration. In addition, the patient had central hypoacusis. Cerebellar tests were consistent with right upper limb dysmetria, but with no dysdiadochokinesia, no hypotonia and no altered results in the Stewart-Holmes test. Finally, the patient had no change in tactile, thermal, vibration, painful or appendicular proprioceptive sensitivity, but presented with a disproportionate, right-sided grade IV hemiparesis with distal brachiocrural predominance. The alternating syndrome with cerebellar syndrome components led to the diagnosis of a brainstem lesion with possible direct or indirect compromise of the right cerebellar hemisphere.

The investigation continued with imaging tests. A computed tomography (CT) of the head showed a hypodense lesion in the posterior fossa with compression of the fourth ventricle, in the pons and midbrain topography, predominantly left-sided. A magnetic resonance imaging (MRI) of the skull showed a lobular expansive lesion in the dorsal portion of the pons, measuring $2.2 \times 2.1 \times 2.0 \mathrm{~cm}$. This lesion was hypointense in T1-weighted images and discretely hyperintense in T2-weighted images, also presenting a heterogenic enhancement after gadolinium infusion and a vasogenic edema extending to the bulb, to the left cerebellar hemisphere and to the mesencephalon (-Figs. 1, 2 and $\mathbf{3}$ ). Since the patient was immunosuppressed, a fungal opportunistic infection was suspected, and, following standardized flow charts to investigate this type of lesion, a CT of the chest was also performed in search for a probable underlying infectious site, which revealed a $4 \mathrm{~mm}$ nodule in the right lower lobe and bilateral apical centrilobular micronodules, with no signs of active disease, pulmonary abscesses or "fungal balls." A bronchoalveolar lavage was also performed and it was negative for Koch bacilli and fungi (both in the direct examination and in cultures).

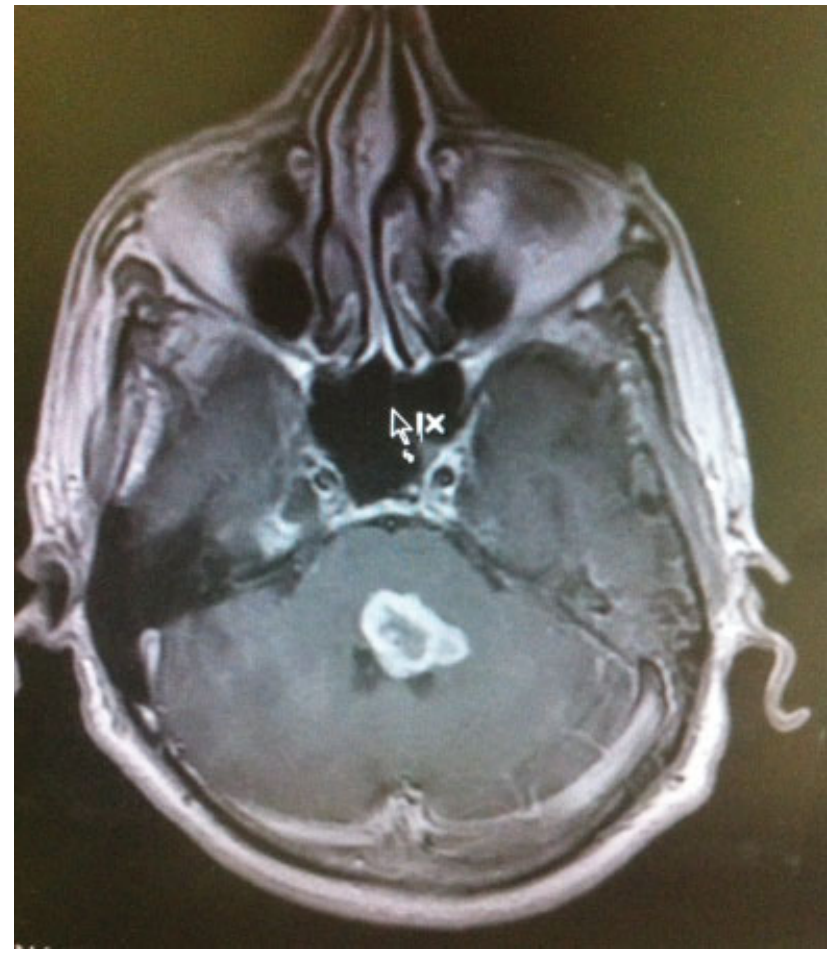

Fig. 1 Axial magnetic resonance imaging enhanced with gadolinium showing an irregular outlined lesion with an isointense center circumscribed by a hypersignal area with contrast medium uptake located in the posterior portion of the pons and in the left middle cerebellar peduncle, and an exophytic growth toward the fourth ventricle.

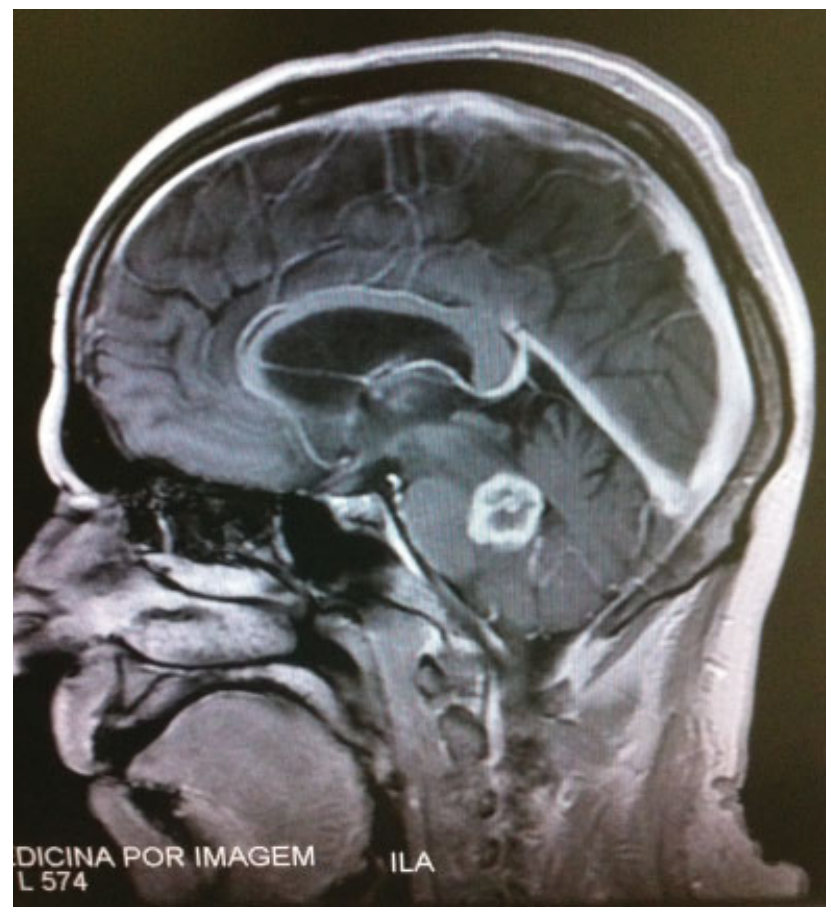

Fig. 2 Sagittal magnetic resonance imaging enhanced with gadolinium showing a lesion with peripheral contrast medium uptake in the posterior portion of the pons and growing toward the fourth ventricle. 


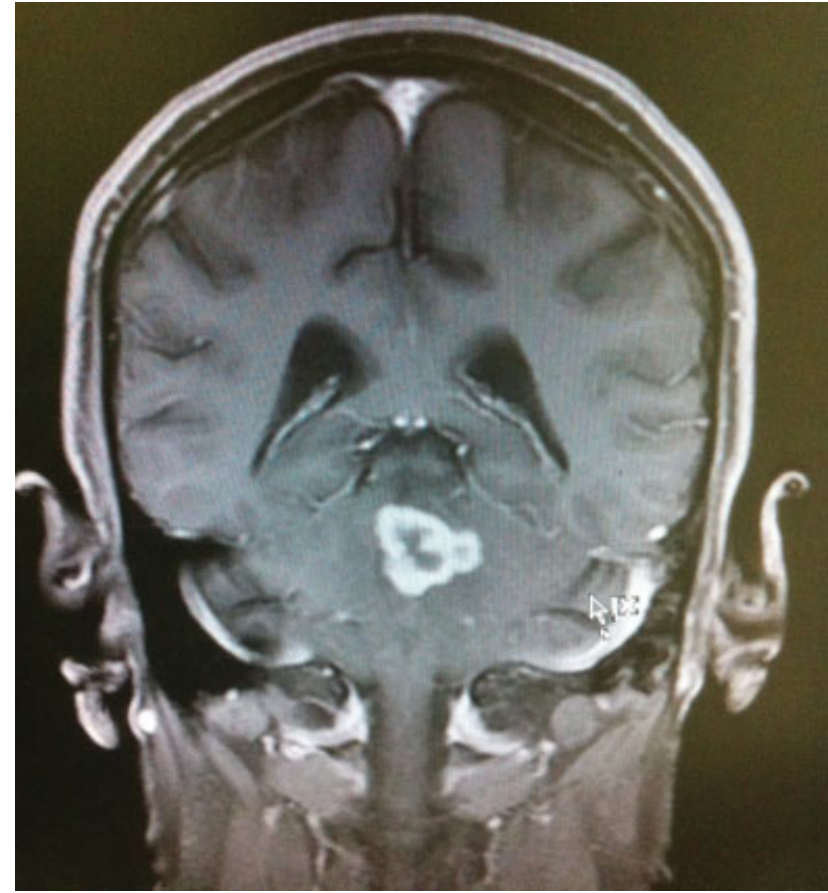

Fig. 3 Coronal magnetic resonance imaging enhanced with gadolinium showing a lesion with peripheral contrast medium uptake and content with intensity similar to the cerebral parenchyma.

With no diagnosis, the patient was submitted to a neurosurgical approach through a telovelar access. Intraoperative visualization aided by a microscope allowed the identification of a red-colored, apparently infiltrative, exophytic lesion. An incisional biopsy of the lesion was attempted, but it was unsuccessful because the lesion was very hardened. A cleavage plane between the lesion and the parenchyma was then identified and dissected, allowing the complete resection of the diseased tissue. After its removal, a macroscopic analysis of the lesion revealed a granulomatous appearance. The histopathologic examination was consistent with a tuberculoid granuloma.

In the early postoperative period, the patient continued to present with the previous deficits and evolved with a worsening of the left facial paralysis (with disfiguring asymmetry) and right palpebral ptosis. These findings improved progressively, and the patient presented good clinical and neurological evolution. On the $10^{\text {th }}$ postoperative day, the patient presented with a sudden reduction of the level of consciousness and anisocoria (with left-sided mydriasis). An urgent CT of the head identified a massive acute subdural hematoma. Although an urgent surgery for subdural hematoma drainage was indicated, the patient died within 2 days.

\section{Discussion}

Approximately one third of the population of the world is infected with M. tuberculosis, and its coinfection with HIV can be the most important factor for systemic infection. ${ }^{1}$ The number of coinfected people is estimated in 3.1 million. $^{8}$ In Brazil, the annual tuberculosis incidence dropped from 51.8 to $38.2 \%$ in the last 2 decades. In addition, there was a $26 \%$ reduction in the incidence and a $32 \%$ reduction in the general mortality due to tuberculosis. ${ }^{9}$

The most common form of tuberculosis of the CNS is tuberculous meningoencephalitis, ${ }^{2}$ followed by expansive focal lesions, mostly supratentorial, with few reported cases involving the brainstem and the cerebellum. ${ }^{2-7}$

Among the CNS infections by $M$. tuberculosis, tuberculomas can account for between 5 and $30 \%$ of all of the expansive brain lesions; however, brainstem lesions remain uncommon, corresponding to between 2.5 and $8 \%$ of the cases. $3,5,6$

In the brain, granulomas or Rich foci can form between the subpial and subependymal layers, and expand to create tuberculomas or abscesses at the cerebral parenchyma; or, more commonly, they break up, causing meningitis. ${ }^{1,10}$ These lesions are more frequent at the corticomedullary junction, especially in the frontal and parietal lobes, due to the hematogenous dissemination of miliary tuberculosis. ${ }^{2}$ The most common clinical manifestation of tuberculomas is headache, as well as signs of intracranial hypertension and focal neurological deficit. ${ }^{2-4}$ Brain abscesses rarely cause fever and alteration in the level of consciousness, but $>25 \%$ of the patients have convulsive crises. ${ }^{11}$

Tuberculomas commonly present as well-delimited, nodular, hardened and avascular lesions, involved by edema and gliosis areas. ${ }^{7}$ At MRI scans, these lesions appear as hypointense or isointense in T1-weighted images, but their appearance in T2-weighted images is different according to their pattern: caseous lesions present a ring pattern with central necrosis; solid lesions show homogeneous enhancement. ${ }^{2}$ There is also a third manifestation, rarer than those previously mentioned, in which the lesion is associated with cysts. ${ }^{7}$

Rapid detection in HIV coinfected patients is crucial, but finding acid-fast bacilli by polymerase chain reaction (PCR) or positive culture is rare. ${ }^{12}$ Neither the tuberculin test $(31 \%$ sensitivity) nor the interferon gamma detection blood test (IGRA test) (60\% sensitivity) can exclude with precision tuberculosis in HIV-positive individuals, especially if CD4 counts are $<200$ cells $/ \mu 1 .^{13}$ Repeated, high-volume lumbar punctures improve the yield of these tests. ${ }^{14}$

The treatment for tuberculosis does not differ significantly in patients coinfected or not with HIV. ${ }^{15}$ The gold standard is the initial institution of isoniazid, pyrazinamide, ethambutol and rifampicin for 2 months. ${ }^{11}$ Rifampicin decreases protease inhibitors and nevirapine plasma levels, and rifabutin is an appropriate alternative. ${ }^{16}$ After the initial phase, isoniazid and rifampicin or rifabutin are continued for between 9 and 12 months. ${ }^{15}$ The use of steroids and the ideal time to start antiretroviral therapy (ART) along with antituberculosis therapy remain controversial. ${ }^{15}$

Although CNS tuberculosis is clinically managed, there are some surgical indications, either for the diagnosis (as in the present case) or for the treatment of the granuloma or of infectious complications, such as the need for ventricular shunts due to changes in cerebrospinal fluid (CSF) dynamics. ${ }^{3-5,8}$

Neurosurgery is imperative for the identification of the causative organism if it has not been otherwise determined and, in selected cases, to reduce the size of the abscess. ${ }^{11}$ Stereotaxic surgery allows the aspiration of virtually any 
abscess with at least $1 \mathrm{~cm}$ in diameter regardless of its location; the aim of the diagnosis should be the maximum possible drainage. ${ }^{11}$ Moreover, it also aims decompression, unless there is a contraindication due to the suspected organism or in relation to the clinical condition of the patient. ${ }^{11}$

A neurosurgical intervention is recommended in abscesses $>2.5 \mathrm{~cm}$ in diameter. ${ }^{17}$ However, data from comparative studies are limited, and this size cannot be regarded as a definite indication for aspiration. ${ }^{11}$ In patients with multiple abscesses, the larger abscesses must be aspirated to ascertain the diagnosis. ${ }^{11}$

In the past 50 years, the prognosis has progressed due to new testing techniques, to antimicrobial therapy regimens, and to the introduction of minimally invasive neurosurgical procedures. ${ }^{18}$ However, mortality in multidrug-resistant HIV-coinfected patients remains extremely high. ${ }^{19}$

\section{Conclusion}

Brainstem tuberculomas can be systemically treated with specific medications and surgically managed in case of failure to respond to the medical treatment. However, the surgical removal of expansive brainstem lesions can be recommended in cases in which the lesion is related to the floor of the fourth ventricle, since this approach is feasible and capable of obtaining good results in the postoperative period.

\section{References}

1 Kwan CK, Ernst JD. HIV and tuberculosis: a deadly human syndemic. Clin Microbiol Rev 2011;24(02):351-376

2 Helmy A, Antoun N, Hutchinson P. Cerebral tuberculoma and magnetic resonance imaging. J R Soc Med 2011;104(07):299-301

3 Gropper MR, Schulder M, Duran HL, Wolansky L. Cerebral tuberculosis with expansion into brainstem tuberculoma. Report of two cases. J Neurosurg 1994;81(06):927-931

4 Gurjar HK, Joshua SP, Agrawal D, Mahapatra AK. Large pontine tubercular abscess treated surgically. Br J Neurosurg 2013;27(01): 134-136

5 Kumar R, Jain R, Kaur A, Chhabra DK. Brain stem tuberculosis in children. Br J Neurosurg 2000;14(04):356-361
6 Winklhofer S, Kollias S. Incidental MRI finding of a pons tuberculoma in a patient with so-far-undiagnosed multisystemic tuberculosis infection. Clin Imaging 2012;36(05):623-625

7 Sridhar K, Ramamurthi B, Vasudevan MC. Cystic tuberculomas of the brain-two case reports. Neurol Med Chir (Tokyo) 2004;44 (08):438-441

8 Barnes PF, Barrows SA. Tuberculosis in the 1990s. Ann Intern Med 1993;119(05):400-410

9 Conde MB, Melo FA, Marques AM, et al; BTA Committee on Tuberculosis; BTA Guidelines on Tuberculosis Work Group. III Brazilian Thoracic Association Guidelines on tuberculosis. J Bras Pneumol 2009;35(10):1018-1048

10 Simmons CP, Thwaites GE, Quyen NT, et al. Pretreatment intracerebral and peripheral blood immune responses in Vietnamese adults with tuberculous meningitis: diagnostic value and relationship to disease severity and outcome. J Immunol 2006;176 (03):2007-2014

11 Brouwer MC, Tunkel AR, McKhann GM II, van de Beek D. Brain abscess. N Engl J Med 2014;371(05):447-456

12 Dragic T, Litwin V, Allaway GP, et al. HIV-1 entry into CD4+ cells is mediated by the chemokine receptor CC-CKR-5. Nature 1996;381 (6584):667-673

13 Syed Ahamed Kabeer B, Sikhamani R, Swaminathan S, Perumal V, Paramasivam P, Raja A. Role of interferon gamma release assay in active TB diagnosis among HIV infected individuals. PLoS One 2009;4(05):e5718

14 Marais S, Thwaites G, Schoeman JF, et al. Tuberculous meningitis: a uniform case definition for use in clinical research. Lancet Infect Dis 2010;10(11):803-812

15 Tan IL, Smith BR, von Geldern G, Mateen FJ, McArthur JC. HIVassociated opportunistic infections of the CNS. Lancet Neurol 2012;11(07):605-617

16 Luetkemeyer AF. Current issues in the diagnosis and management of tuberculosis and HIV coinfection in the United States. Top HIV Med 2010;18(04):143-148

17 Mamelak AN, Mampalam TJ, Obana WG, Rosenblum ML. Improved management of multiple brain abscesses: a combined surgical and medical approach. Neurosurgery 1995;36(01):76-85, discussion 85-86

18 Brouwer MC, Coutinho JM, van de Beek D. Clinical characteristics and outcome of brain abscess: systematic review and metaanalysis. Neurology 2014;82(09):806-813

19 Daikos GL, Cleary T, Rodriguez A, Fischl MA. Multidrug-resistant tuberculous meningitis in patients with AIDS. Int J Tuberc Lung Dis 2003;7(04):394-398 